\title{
Consideraciones previas sobre las formas del tipo tafone y otras estructuras menores en la vertiente norte del Pão de Açúcar, Rio de Janeiro - Brasil
}

\author{
Initial considerations on the forms of tafoni type and \\ minor structures on the north face of the Sugar Loaf, Rio \\ de Janeiro - Brazil
}

RODRIGUES WALDHERR, F.'; VIDAL-ROMANI, J. R. ${ }^{2}$; WILIANS DE OLIVEIRA RODRIGUES, S. ${ }^{3}$

${ }^{1}$ Faculdade de Geologia. Universidade do Estado do Rio de Janeiro. Rua São Francisco Xavier, 524, Maracanã, CEP 20550-013, Rio de Janeiro, RJ, Brasil. felipewald@gmail.com

${ }^{2}$ Instituto Universitario de Geología. Universidad de Coruña. ESCI (piso-3). Campus de Elviña. 15071 Coruña. juan.vidal.romani@udc.es

3 Faculdade de Ciências e Tecnologia, Curso de Geologia. Universidade Federal de Goiás. Rua Mucuri, s/n, Parque Itatiaia, CEP 74968-755, Aparecida de Goiânia, GO, Brasil. swor@ufg.br

https://doi.org/10.17979/cadlaxe.2018.40.0.4917

enviado 2/2/2018 aceptado 12/12/2018

\section{Resumen}

Las cavidades tipo tafone en los afloramientos rocosos granítico-gnéisicos de Rio de Janeiro habían pasado inadvertidas hasta ahora para los investigadores a pesar de ser formas frecuentes tanto en las zonas costeras como en las montañosas adyacentes. Poco se ha discutido, hasta ahora, sobre el origen de estas formas en Brasil atribuidas habitualmente a la al- 
teración subedáfica y subaérea. Este trabajo presenta una breve descripción de las cavidades del tipo tafone encontradas en la pared norte del domo Pão de Açúcar y discute otras hipótesis genéticas alternativas a las habituales para estos rasgos geomorfológicos característicos del basamento granítico-gnéisico del sureste brasileño.

Palabras-clave: Tafoni, Formas menores, Geomorfología granítica-gnéisica, Pão de Açúcar, Sureste de Brasil.

\begin{abstract}
The tafone-type cavities in the granitic-gneissic rocky outcrops of Rio de Janeiro had so far gone unnoticed by researchers despite being frequent forms in the rocky outcrops of the area in both the coastal and adjacent mountainous areas. Little has been discussed, until now, about the origin of these forms in Brazil usually attributed to sub-soil and/or subaerial wathering. This paper presents a brief description of the cavities of the tafone type found in the northern wall of the Pão de Açúcar dome. They are discussed alternative genetic hypotheses to the usual for these characteristic geomorphological features of the graniticgneissic basement of southeastern Brazil.
\end{abstract}

Key-words: Tafoni, Minor forms, Granite-gneiss geomorphology, Sugar Loaf, Southeast Brazil. 


\section{INTRODUCCIÓN}

Existe una abundante literatura sobre el origen, descripción y distribución geográfica de cavidades tipo tafone y estructuras asociadas, alvéolos y panales (honeycombs) referida a todo el Mundo aunque, sorprendentemente hasta hace poco tiempo, no eran mencionados casos de Brasil a pesar de que es allí donde se encuentran los tafoni de mayores dimensiones en todo el Mundo, (Auler A.S. et al. 2007; Waldherr et al. 2018). En Brasil se han descrito tafoni especialmente en los macizos residuales y lineamientos montañosos de la región Noreste y Sureste de Brasil (Bigarella, 1994; Maia et al., 2015; Maia e Nascimento 2018). En diferentes zonas del Estado de Rio de Janeiro tanto en macizos rocosos costeros como en las zonas montañosas interiores de la Serra do Mar los tafoni son formas frecuentes. Hasta ahora su origen se ha venido considerando, (Maia e Nascimento 2018), como debido a procesos de alteración subedáficos o relacionados con el perfíl de meteorización de la roca. Quizás por esta razón algunos autores, (Petit, 1971; Twidale, 1982), han llegado a considerar el desarrollo de estas formas incompatible con el clima tropical, (Migón, 2006), al pensar que la intensidad de la meteorización química tipica de zonas tropicales puede inhibir el desarrollo de tafoni, algo que obviamente no es cierto (Maia e Nascimento 2018; Waldherr et al. 2018). Independientemente de sus dimensiones, que son muy variadas, una de las características mas distintiva de los tafoni es que las paredes internas de estas cavidades pueden verse afectadas por una activa desagregación granular o incluso pueden estar recubiertas de protuberancias o depresiones, aisladas o asociadas en panal (honeycomb), (Vidal-Romani y Twidale, 1998; Twidale y
Vidal-Romani, 2005). Sin duda la existencia de eatructura en panal (honeycomb), para el caso de los tafoni en rocas magmáticas o sedimentarias se ha convertido en un criterio diagnóstico para la definición de un tafone.

En el Estado de Rio de Janeiro, el estudio de las cavidades de tipo tafone en los afloramientos rocosos granítico-gnéisicos habían recibido hasta ahora escasa atención por parte de los geomorfólogos, quizás por tratarse de formas aisladas, de pequeñas dimensiones o por situarse en zonas de difícil acceso. Pero en los últimos años, se han incrementado las citas bibliográficas sobre el hallazgo de formas tipo tafone y sus estructuras asociadas (honeycomb). Especialmente son frecuentes en las descripciones de montañeros y escaladores (que los usan como elementos de referencia en sus actividades deportivas), aunque como antes se dijo han estado casi ausentes, hasta ahora, en los trabajos geomorfológicos.

En Rio de Janeiro las cavidades tipo tafone se desarrollan en las paredes laterales de los domos rocosos. Son frecuentes en los domos de Pão de Açúcar, Pedra da Gávea, Dois Irmãos y Cabritos. Otros domos costeros como Babilônia y Cantagalo, también presentan este tipo de formas menores aunque en menor abundancia, y lo mismo sucede en el Parque Nacional da Tijuca.

Este trabajo se refiere a los tafoni situados en la vertiente norte del domo Pão de Açucar, orientada hacia el interior de la Baía de Guanabara donde puede observarse una amplia distribución de estas cavidades de tamaños muy diferentes, recubriendo los afloramientos de gneis glandular (augen gneiss). En el domo Pão de Açucar los tafoni de mayor tamaño tienden a presentarse, principalmente, en el tercio basal del domo, por encima de los 160 metros de altura y 
siempre relacionados con una gran diaclasa de descamación visible en el paredón rocoso, conocida como "La Ibis del Pão de Açúcar" por su forma semejante a esta ave. La diaclasa se orienta diagonalmente al desarrollo longitudinal del domo y asociadas a ella se localizan hasta cinco tafone, (Figuras 1 y 2). Estas cavidades tienen el carac- terístico desarrollo de los tafone: bóvedas en arco en cuyo interior se pueden apreciar los modos de desagregación descritos en la literatura como: desagregación granular, en placas (flaking), desarrollo de alveolos tanto aislados como en grupos (honeycomb o estructura en panal) asi como también protuberancias convexas, mamelonares.

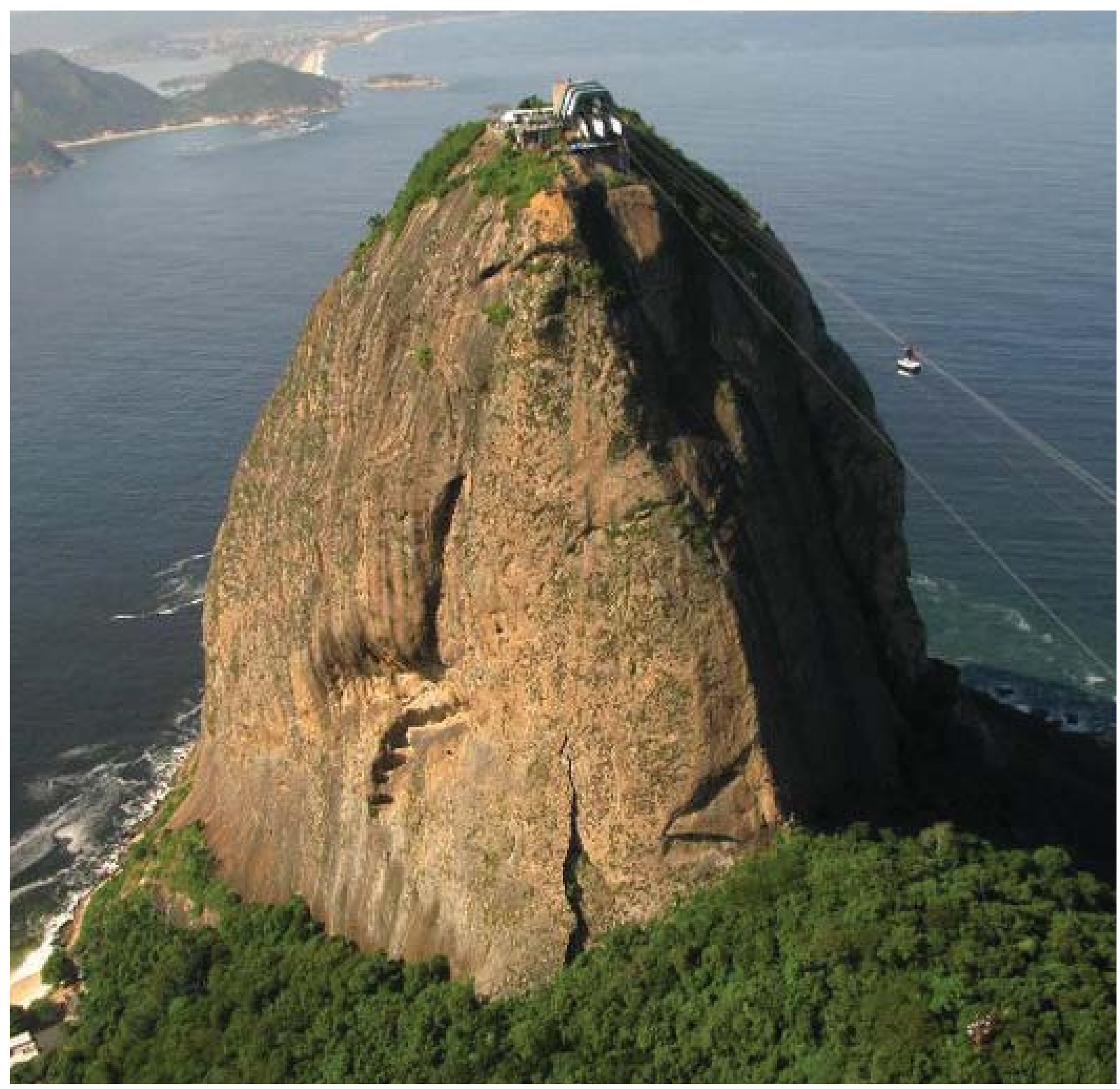

Fig. 1. Vertiente norte del domo Pão de Açúcar (a la izquierda) orientada hacia la Bahía de Guanabarà. Las cavidades de tipo tafone están dispuestas en la diagonal y alrededor de la fractura de descamación suspendida. La vertiente sur del domo (a la derecha) está orientada hacia el Océano Atlántico. (Fotografía cortesía de: Thiago Haussig). 


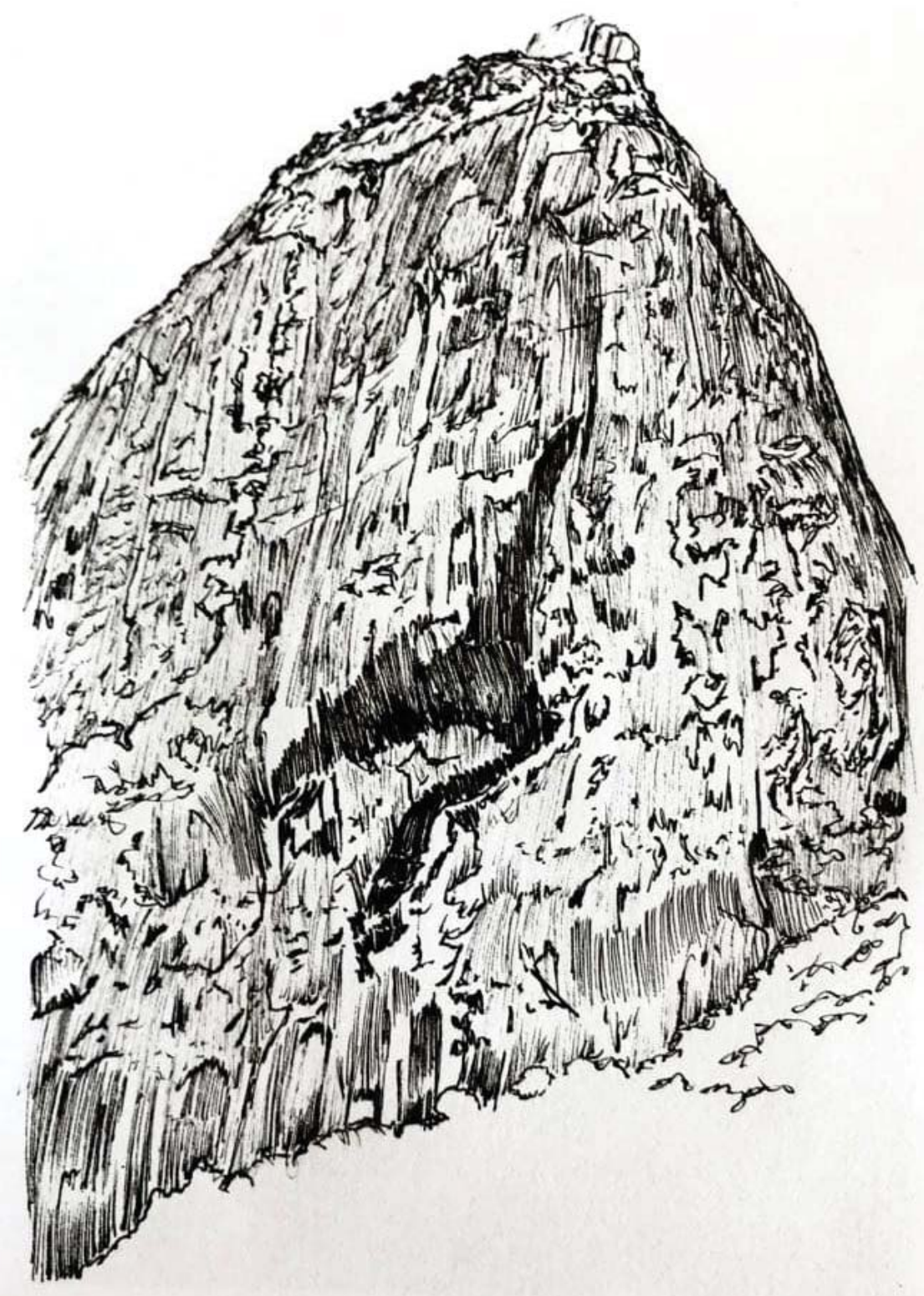

Fig. 2. La Ibis del Pão de Açúcar es también una conocida vía de escalada para los montañeros en la ciudad de Rio de Janeiro, Brasil. (Dibujo de Marcelo Motta de Freitas usando la fotografía de Henrique de O. Felippe como referencia).

\section{SITUACIÓN GEOGRÁFICA}

El domo de Pão de Açúcar se ubica en el barrio de Urca, zona sur del municipio de Río de Janeiro. La roca se sitúa en la entrada de la Baía de Guanabara alcanzando una altura máxima de 396 metros. El Pão de Açúcar ha sido descrito por viajeros y naturalistas desde el siglo XVI (Figura 3) siendo considerado ícono natural e histórico de la ciudad de Río de Janeiro y de Brasil. Durante el 31st International Geological Congress, en junio de 2000, el domo fue declarado como uno de los principales sitios geológicos de interés mundial como indica una placa conmemorativa adosada a la pared rocosa. 


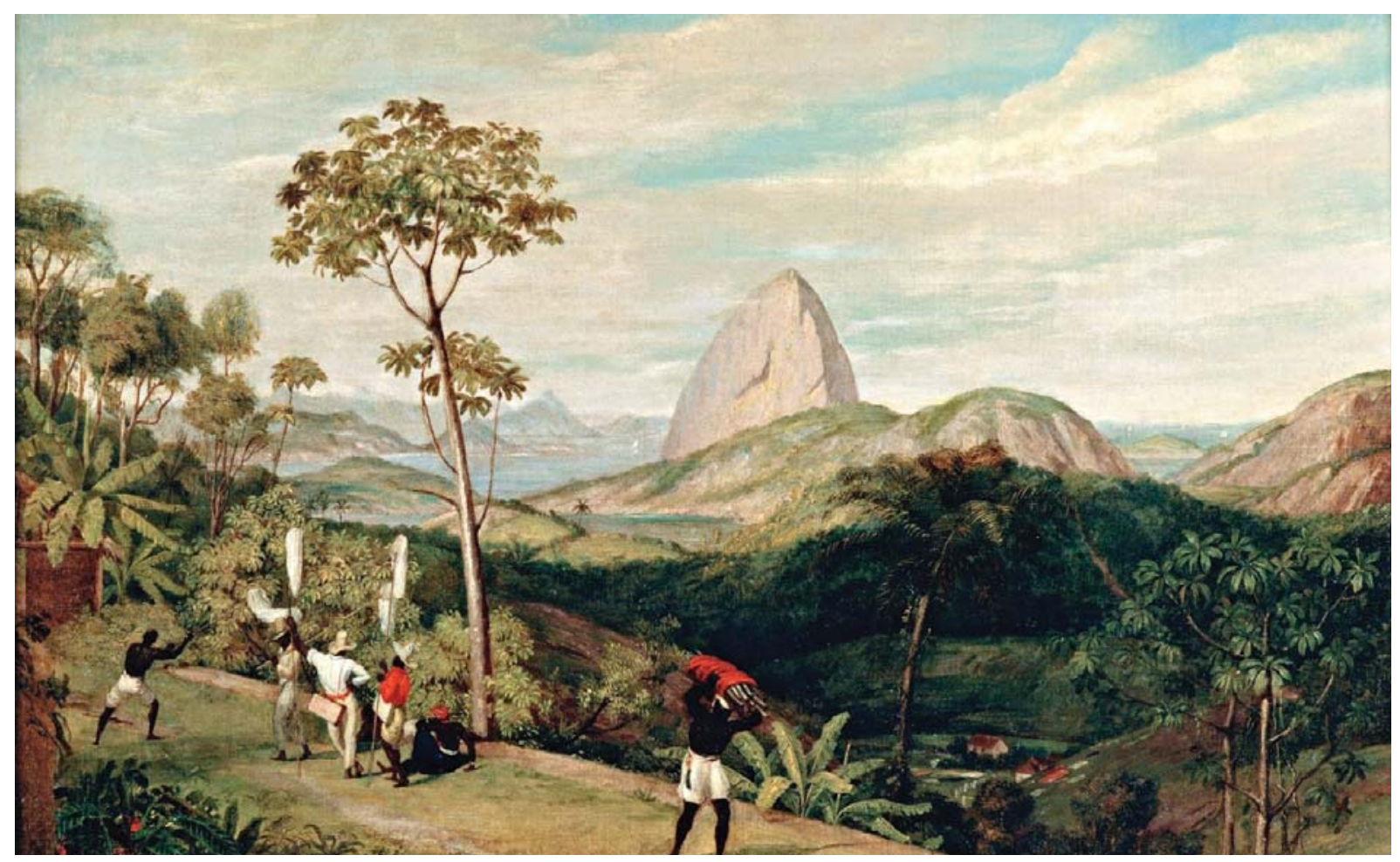

Fig. 3. En la obra de Charles Landseer, de principios del siglo XIX, se puede observar la cavidad denominada "Íbis" en la vertiente norte del Pão de Açúcar. (Landseer, 1827)..

\section{LITOLOGÍA Y ESTRUCTURA}

El sustrato geológico del domo Pão de Açúcar y su entorno, está formado por paragneises afectados por un metamorfismo de alto grado de edad Meso-NeoProterozoica que han sido intruídos por un granitoide post-colisional del Neoproterozoico (560 millones de años) y posteriormente por diques de diabasa del Cretácico (Figura 4) (Silva y Ramos, 2002; Valeriano et al., 2003). En la cara norte del Domo Pão de Açúcar se reconocen algunas fracturas de descamación (sheet structure) y otras asociadas a aquellas que se están abiertas en la pared. Estas discontinuidades corresponden a la estructura desarrollada en el cuerpo rocoso durante la etapa de intrusión del granitoide post-colisional en el paragneis encajante (Valeriano et al., 2003). El domo del Pão de Açúcar está formado principalmente por el citado gneis glandular (augen gneiss) (ver Figura 4). En la vertiente sur por el contrario aunque está muy bien desarrollada una estructura de flujo, (Fig. 12), apenas hay discontinuidades abiertas (ver apartado 5.2)

\section{METODOLOGIA}

Durante julio y agosto de 2018 se realizaron trabajos de campo para obtener datos exclusivamente morfológicos de las cavidades de tipo tafone, localizadas en la pared norte del domo Pão de Açúcar. La existencia de tafoni en la zona era conocida a partir de las fotografías tomadas por los escaladores y, posteriormente mediante las imágenes de alta resolución obtenidas del Image Digital Globe 2018 (Google Earth Pro) en modo 3D (Figura 5), donde los tafoni descritos en este 


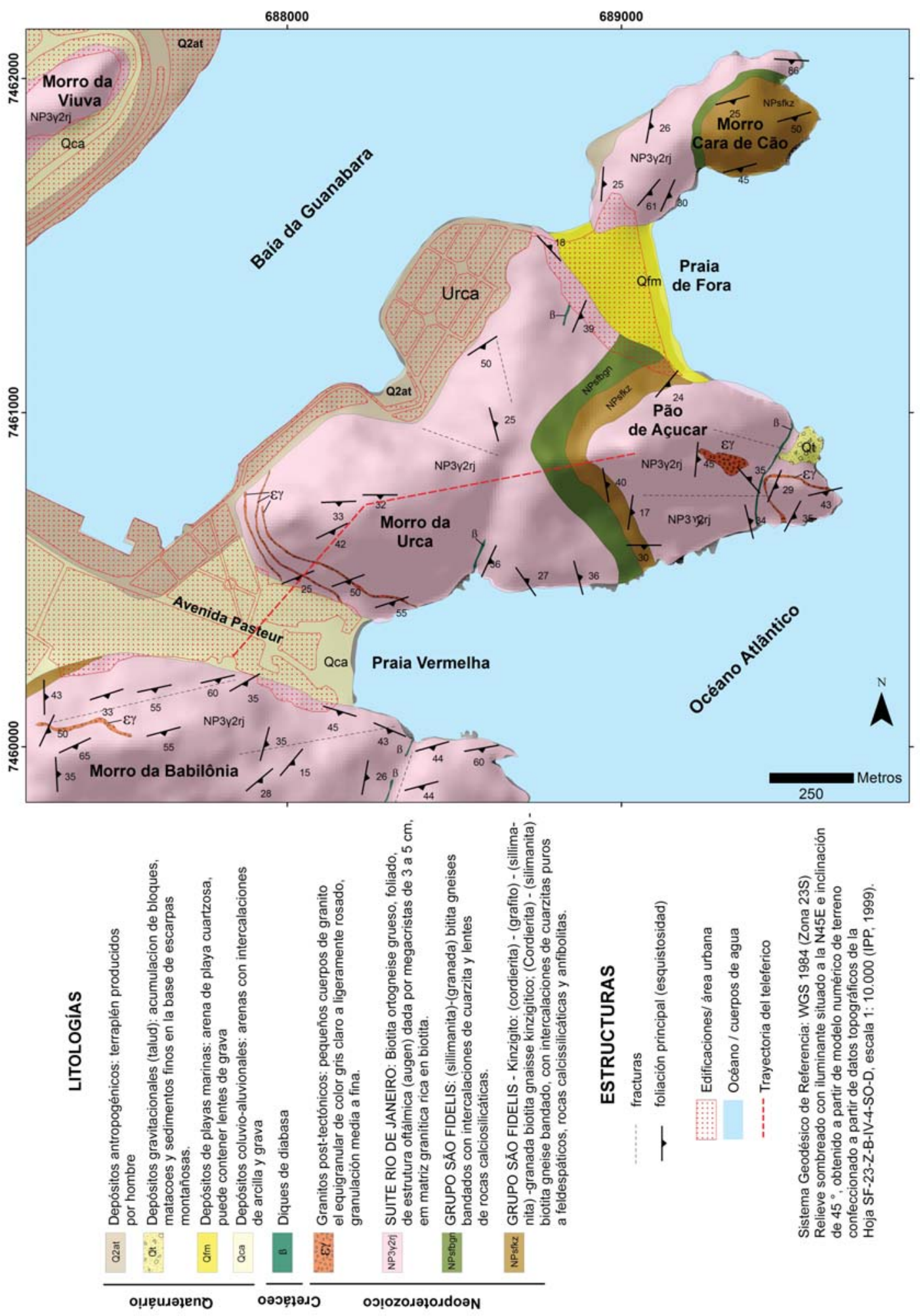

Fig. 4. Mapa geológico del domo de Pão de Açúcar y de su entorno inmediato. (modificado de Valeriano et al., 2003) 
trabajo se señalan con una numeración del 1 al 5. Mediante estas imágenes se pudo realizar un reconocimiento detallado de las cavidades aun de las mas inaccesibles por estar situadas a mayor altura. Posteriormente, los equipos de escalada obtuvieron imágenes de detalle en la base del tafone número 1 (Figura 5) siguiendo la llamada vía de escalada Íbis (Figura 2).

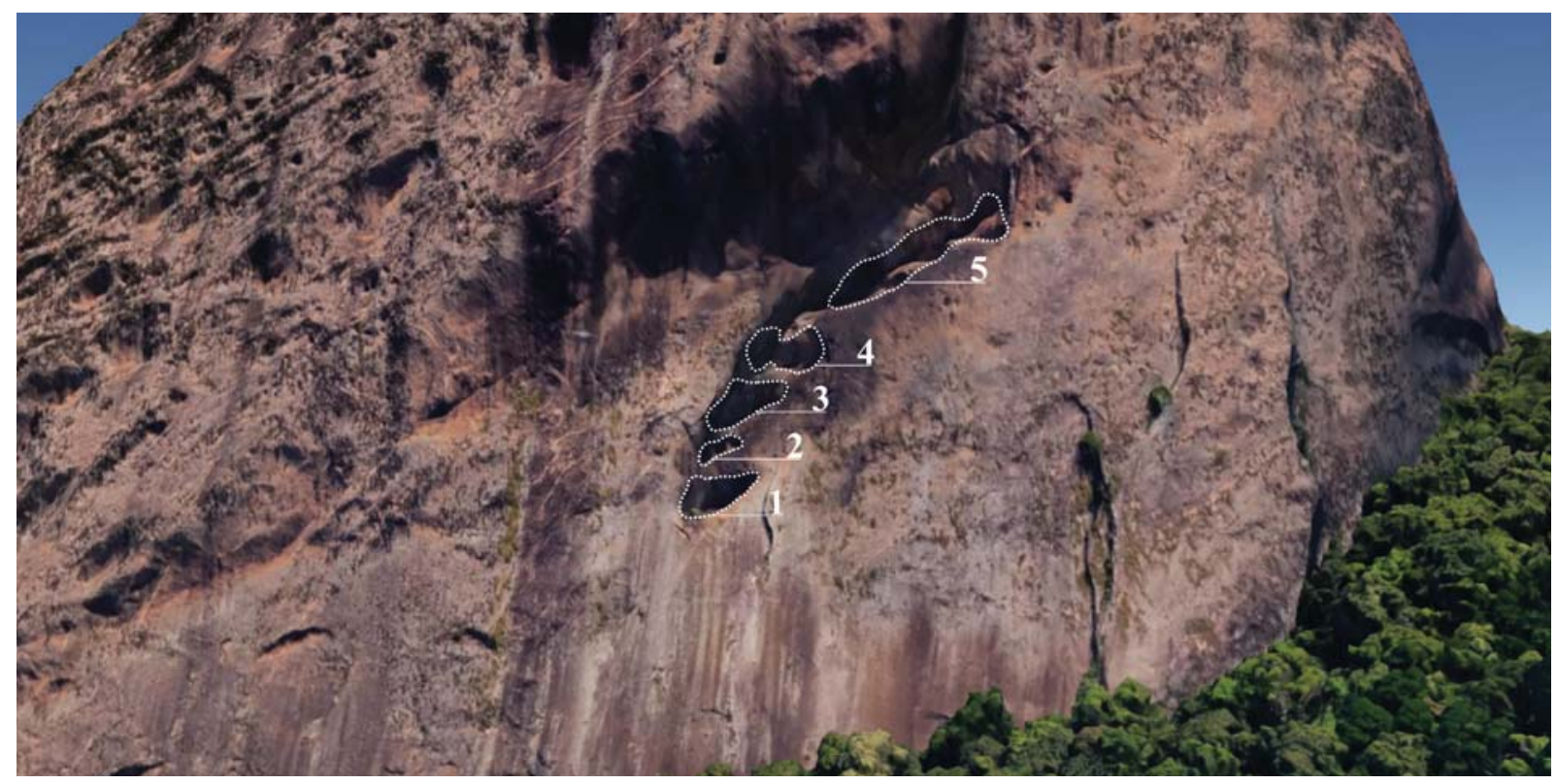

Fig. 5. Los tafoni de mayores dimensiones (número 1 al 5) se sitúan en la vertiente norte del Pão de Açúcar. El tafone número 5 constituye la meseta de Íbis y es el mayor de todos. En la imagen se aprecia la relación entre la situación de los tafoni y el control estructural definido por la foliación del gneis glandular (augen gneis) y el sistema de discontinuidades. (Fuente: Image Digital Globe 2018 - Google Earth Pro).

Como antes se indicó las características morfológicas de las cavidades tipo tafone son similares a las definidas en la literatura previa, (Vidal-Romani, 1984, 1989, 2008; Twidale y Vidal-Romani, 2005); Maia y Nascimento, 2018; Michal Filippi et al., 2018), para estas formas en otras partes del Mundo. En la clasificación de las estructuras menores asociadas a la bóveda interna de los tafoni se tuvo en cuenta la propuesta de Mayor Rodríguez (2011) y Michal Filippi et al. (2018).

Según la Guía de Espeleología del Centro Nacional de Investigación y Conservación de Cuevas (CECAV-Icmbio, 2010) las cavidades del Pão de Açúcar de acuerdo con sus dimensiones pueden ser definidas como "abrigo" un tipo de cavidad cuya característica principal es tener un desarrollo horizontal mayor que su altura.

\section{RESULTADOS}

\subsection{La vertiente norte del domo de Pão de Açúcar}

En la vertiente norte la aproximación a las cavidades se realizó escalando el paredón rocoso con una pendiente entre $65^{\circ}$ y $70^{\circ}$ y que es la principal ruta de escalada denominada la Vía Ibis con un grado de dificultad alto (Figura 6). Los tafoni estudiados 
en el Domo de Pão de Açúcar se asocian claramente a la estructura de exfoliación formada durante la etapa intrusiva de la roca (Valeriano et al., 2003) quees cuando la estructura del domo queda definida. Las superficies de descamación (sheet structure) (Vidal-Romani, 2008; Vidal-Romani et al., 2014; Roqué et al., 2013) se desarrollan especialmente durante la etapa intrusiva y en el contacto con la roca encajante que debe ser eliminada por erosión para dejar al descubierto el domo con su envuelta de lajas de exfoliación (sheet structure). Posteriormente en un proceso gradual las envueltas se desprenden cayendo por gravedad hasta la base del domo. En domo de Pão de Açúcar es durante este proceso final de descamación cuando se pusieron al descubierto los tafoni desarrollados inicialmente en los contactos entre hojas (sheets) adyacentes. En las figuras $6,7,8,9$ y 12 pueden reconocerse algunos restos de la sheet structure adheridos al domo en la parte superior y laterales. Debemos suponer que los desprendimientos de las distintas láminas de exfoliación a lo largo del tiempo han hecho desaparecer gran parte de los tafoni que se habrían desarrollado inicialmente. En casos similares estudiados en otras zonas del Mundo (Vidal-Romani, 2008; Vidal-Romani et al., 2014), una vez que la zona afectada por la tafonización queda expuesta en superficie, (después del desprendimiento de alguna de las hojas de la sheet structure), comenzará a degradarse el volumen de la roca afectada por la tafonización (Vidal-Romani, 2008). El proceso más eficiente es la desagregación granular que se produce en el interior de lo que luego será la cavidad del tafone. Las imágenes fotográficas suministradas por los escaladores permiten constatar además otro efecto descrito en la literatura que es la descamación en placas o flaking en la pared interna de algunos tafoni.

La actividad de descamación y la desagregación granular también queda probada por las acumulaciones de suelos residuales (Figuras 7 y 10), en la base de algunos de los tafoni cuando están protegidos de la erosión por la escorrentía superficial.

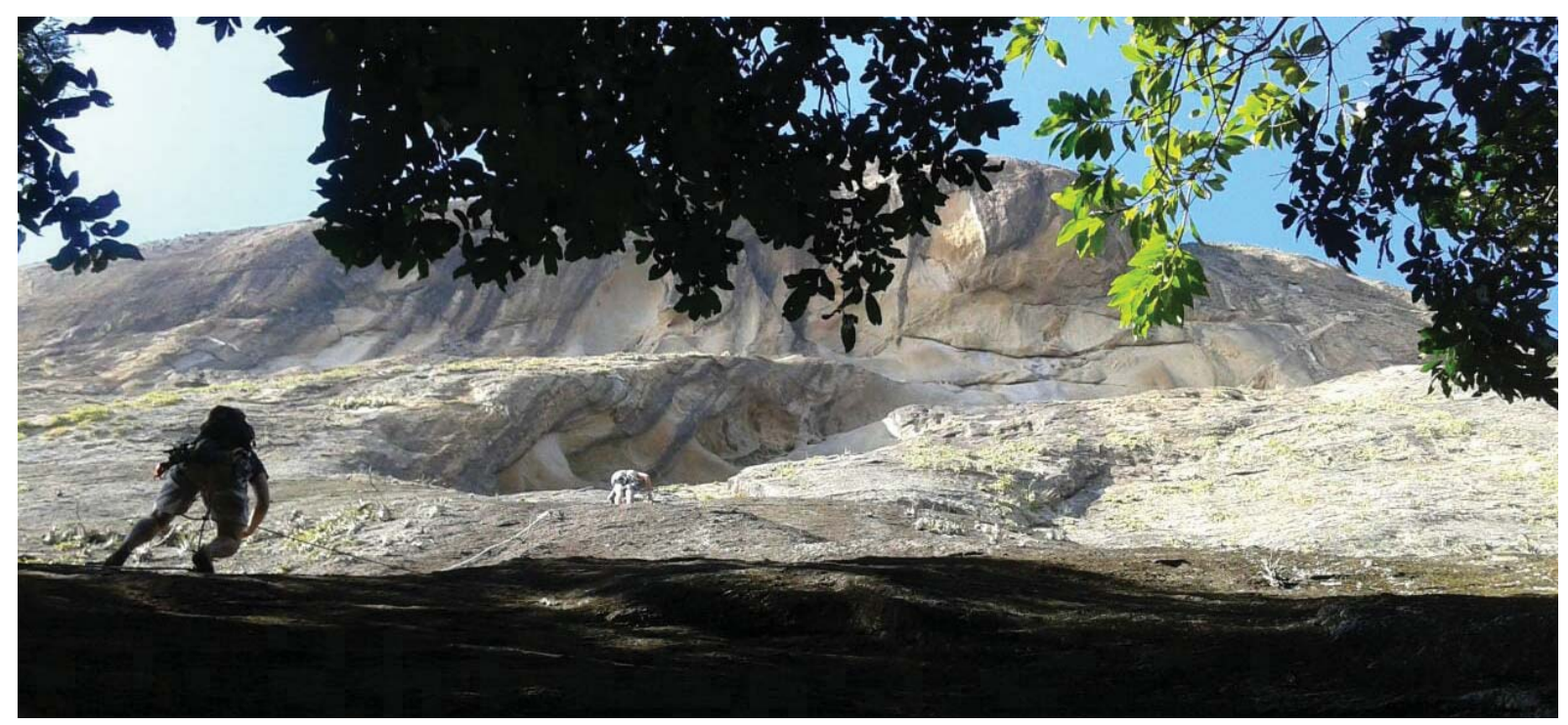

Fig. 6. La subida se realizó por la vía de escalada Ibis. Se pudo llegar cerca de la cavidad número 1 realizando el levantamiento de datos geológico-geomorfológicos sobre los tafoni y estructuras asociadas en la vertiente norte del domo Pão de Açúcar. (Fotografía de Felipe Waldherr). 
Como ya se dijo la formación de tafoni no está generalizada a toda la pared sino que se limita a algunos puntos asociados a las discontinuidades abiertas (Figuras $7 \mathrm{y}$ 8). El mismo sistema de discontinuidades, parcialmente abierto, canaliza el debil flujo de filtraciones de agua de la lluvia y con el los materiales solubilizados durante los procesos biosedimentarios desarrollados en el interior del sistema fisural (Figura 7).

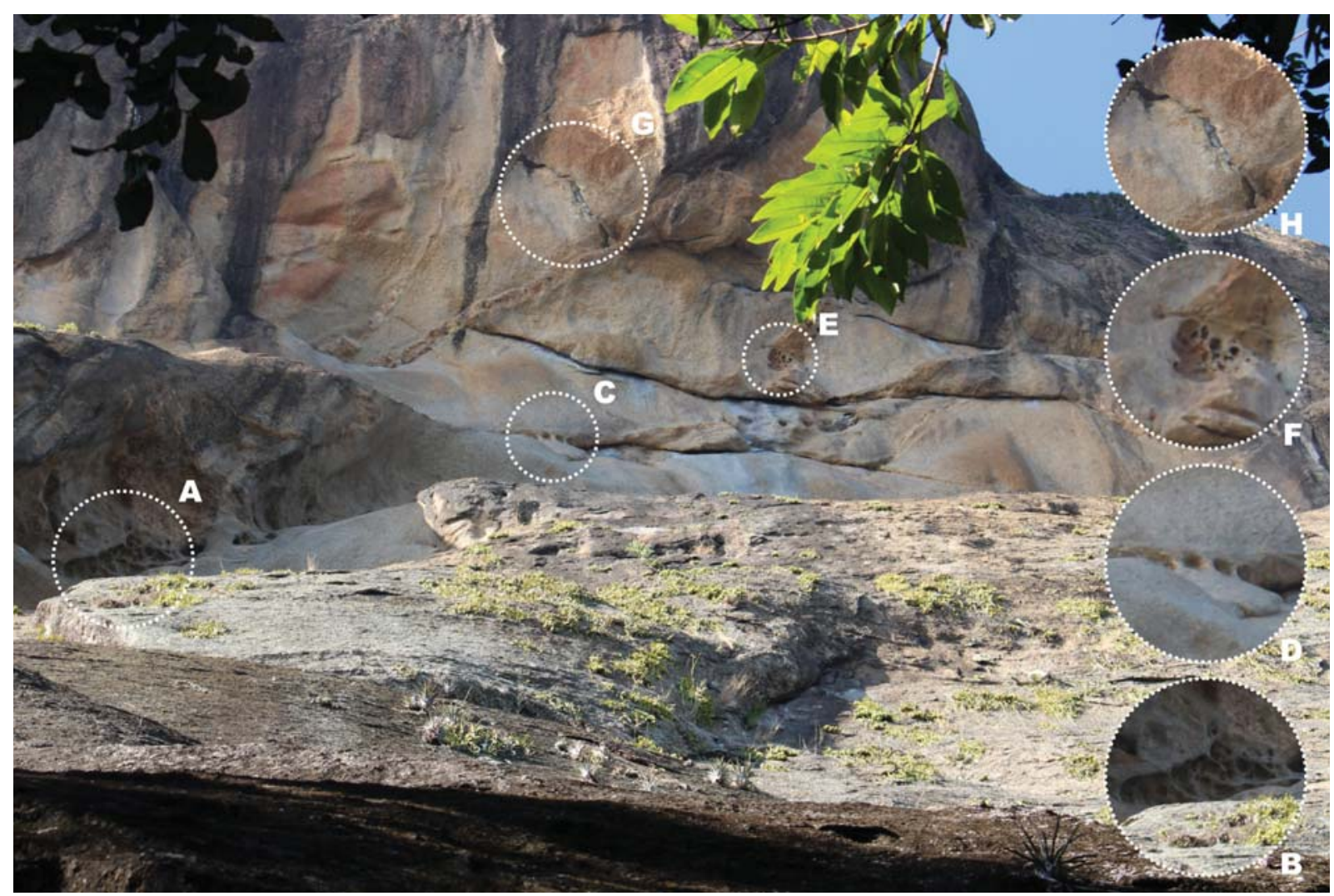

Fig. 7. La presencia de los tafoni, estructuras asociadas y sistema de discontinuidades en la vertiente norte del Pão de Açúcar. A-B) Registro de estructuras menores de panales (honeycombs); C-D) Presencia de alvéolos o arcadas lenticulares entre los planos de fractura (planos subverticales y verticales); E-F) Estructura en panal (honeycombs) sobre una concavidad en la parte inferior de la fractura de descamación suspensa; G-H) Disposición de venas de pegmatitas. Los escurrimientos de agua desde la parte mas alta del domo permiten la colonización, probablemente por líquenes, en la pared rocosa protegida de la lluvia. A la derecha de $\mathrm{C}$ y por debajo de $\mathrm{E}$ pueden verse en color gris claro los depósitos de ópalo biogénico formados en el interior de las fisuras entre la sheet structure (Caldcleugh 1829). (Fotografía: Felipe Waldherr). 


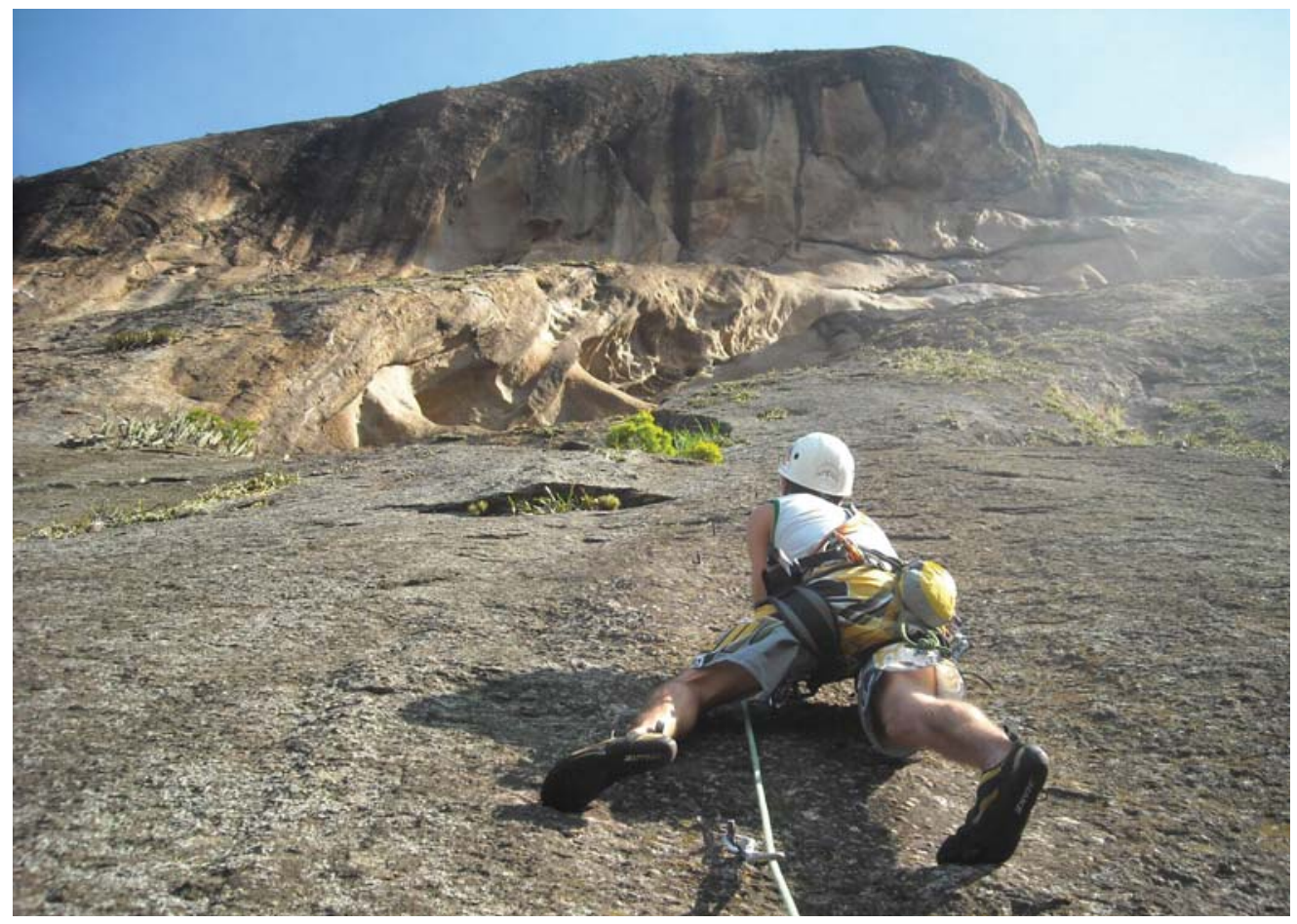

Fig. 8. Cavidades tipo tafoni observadas en la vía Íbis. La enorme fractura de descamación en extraplomo situada en la parte superior de la imagen corresponde a la parte de la sheet structure aun no desprendida del cuerpo del domo. (Fotografía cortesía del Grupo de Montañismo Rocks in Rio).

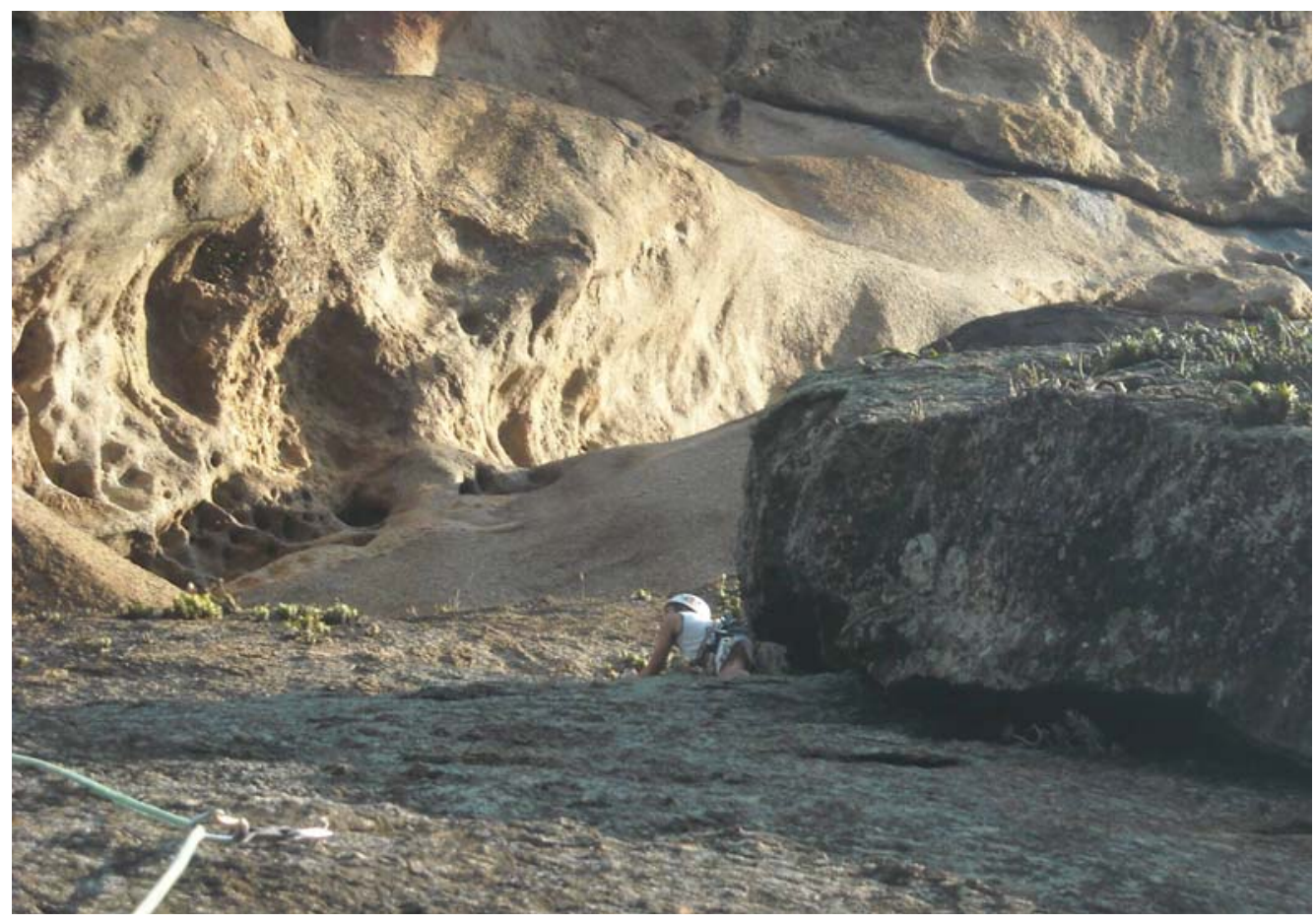

Fig. 9. Aspecto del interior del tafone número 4 con la bóveda recubierta por una estructura en panal (honeycomb) bastante bien desarrollada y con dimensiones centimétricas y separadas por tabiques intermedios. (Imagen cortesía del Grupo de Montañismo Rocks in Rio). 


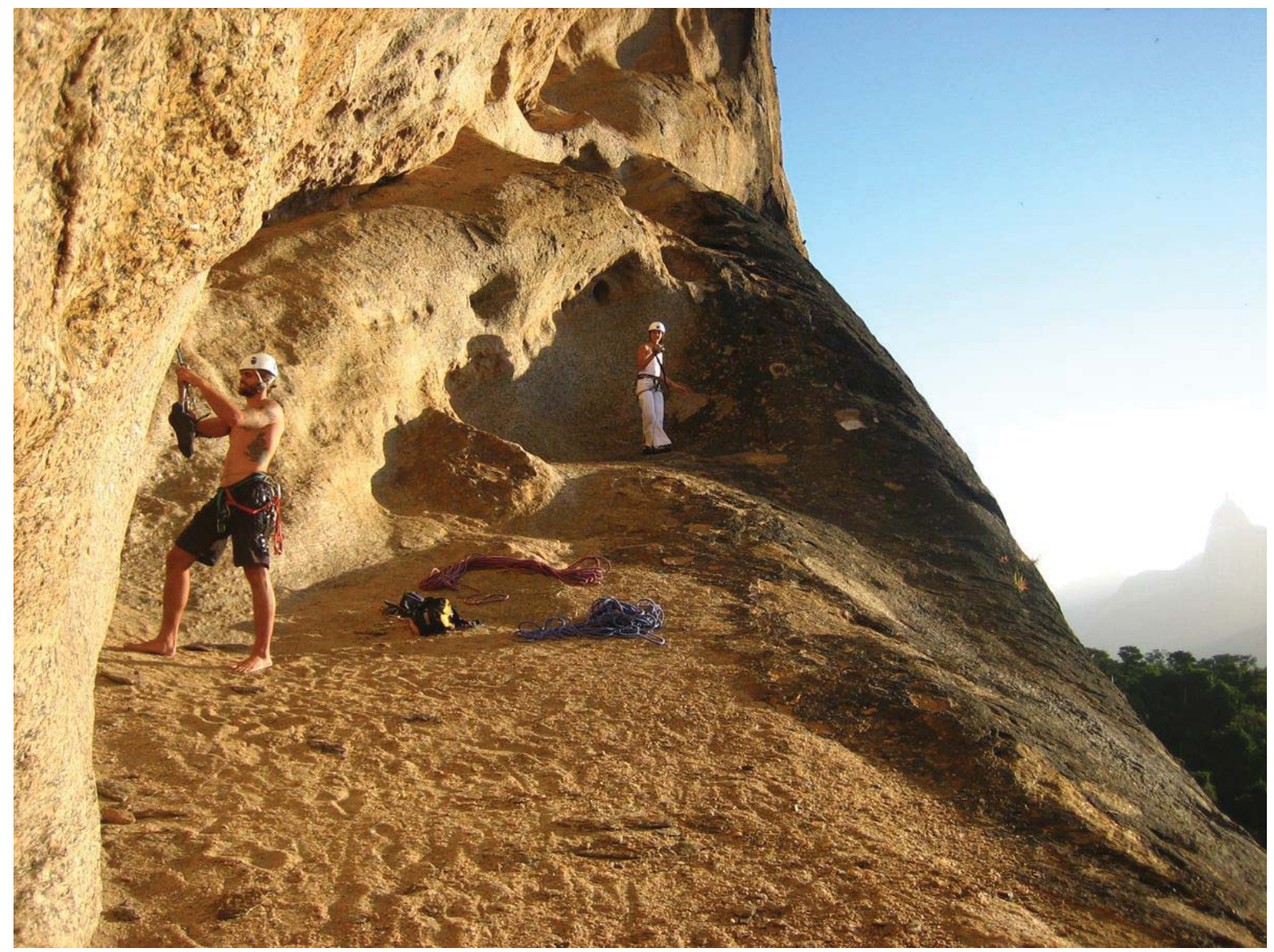

Fig. 10. Aspecto del interior del tafone número 4 con la bóveda recubierta por una estructura en panal (honeycomb) bastante bien desarrollada y con dimensiones centimétricas y separadas por tabiques intermedios. (Imagen cortesía del Grupo de Montañismo Rocks in Rio).

\subsection{Comparación con la vertiente sur del Pão de Açúcar}

La vertiente sur del domo de Pão de Açúcar muestra una diaclasa de descamación (sheet structure) desde la cumbre hasta la base de la formación rocosa, denominada "Lagartão" (ver Figura 11). La pared rocosa que forma la vertiente sur del Pão de Açúcar no presenta ningún replano intermedio o cavidades tipo tafone de grandes dimensiones (tan solo algunas de dimensiones menores asociadas a la gran fisura vertical situadas a diferentes altitudes y que son conocidas por los escaladores como "Agujero de la Gallina" y "Salón Azul" en la vía de escalada "Chaminé Stop"). Pero al contrario de lo que ocurre con las cavidades desarrolladas en la pared norte se trata de cavidades ocultas, no expuestas y asociadas a la fractura de descamación del Pão de Açúcar. 


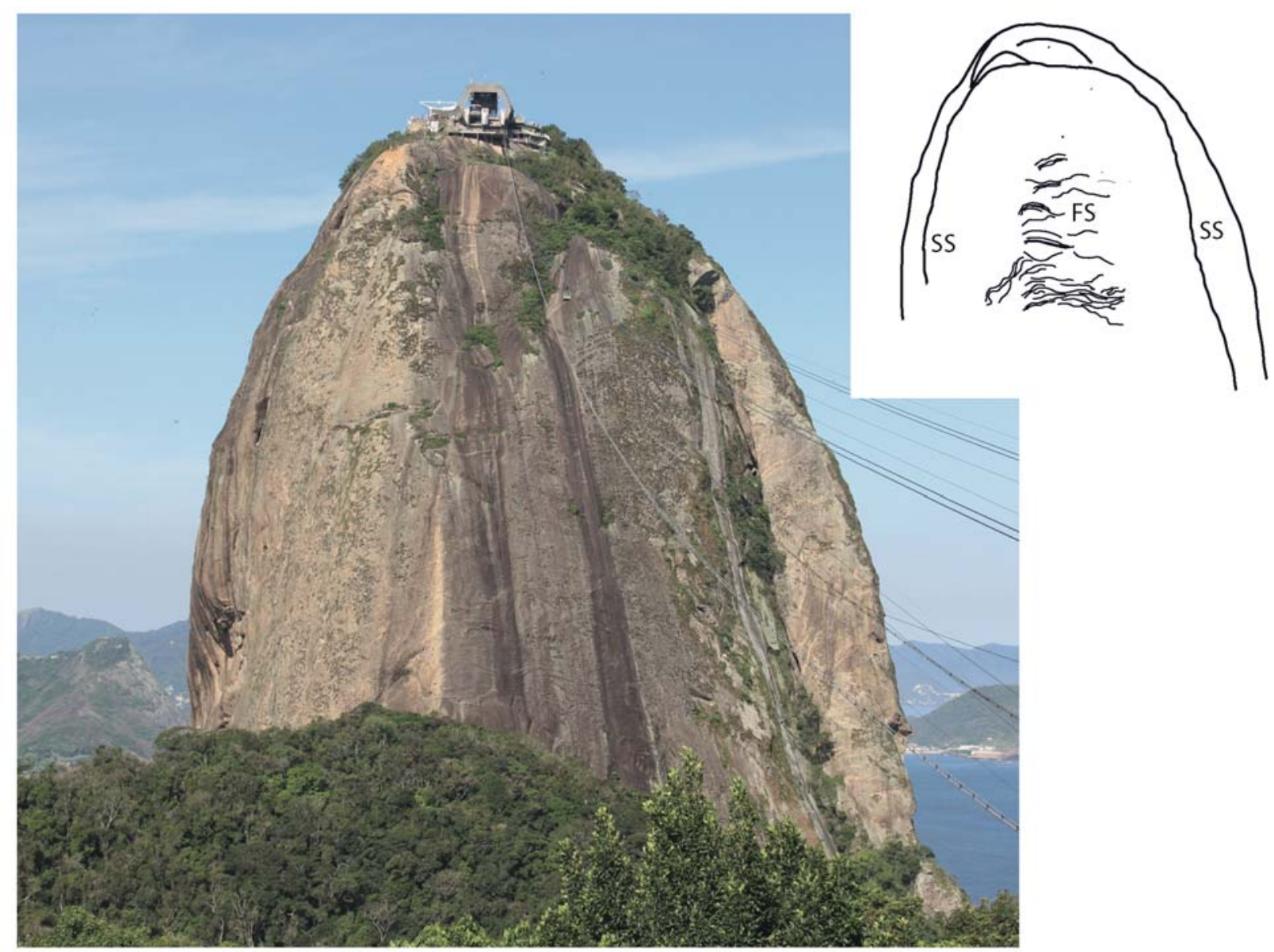

Fig. 11. Pared Sur del domo Pão de Açúcar con desarrollo de estructuras de flujo (F.S.) en la zona central del domo. En el contorno se reconocen aun los restos de distintas hojas de la sheet structure inicial (S.S.). (Fotografía de Felipe Waldherr).

\section{DISCUSIÓN}

En los terrenos graníticos el diseño en superfície (geomorfología) (Twidale y Vidal Romaní, 1994; Vidal Romaní y Yepes, 2004). habitualmente se atribuye a la erosión y/o la meteorización física o química de la roca. Esta es sin embargo una idea demasiado simplista pues postula incluso un origen exógeno para la sheet structure que se suele identificar como un sistema de diaclasas de descompresión, (Migon, 2006; Gutiérrez y Gutiérrez, 2016; Vidal Romani 2004). Otros investigadores, sin embargo, (Vidal Romani 2004; Twidale y Vidal Ro- maní, 1994, 2005) interpretan los paisajes rocosos graníticos como asociaciones de formas, de diversas dimensiones, definidas esencialmente a partir de las discontinuidades generadas durante la etapa final de intrusión magmática cuando la roca aun estaba en el interior de la litosfera (Arzi 1978). Según Twidale y Vidal Romaní, (1994, 1995, 2005) la meteorización superficial de las rocas magmáticas plutónicas aporta muy poco al diseño final de un paisaje granítico pues la mayor parte de las formas (en este caso el contorno del domo) se ha generado durante la etapa intrusiva, dentro de la litosfera. Durante una colisión con 
subducción entre placas litosféricas la roca magmática (mush) generada por la fusión se moviliza ascendiendo hacia la superfície terrestre en forma de cuerpos individuali- zados. Generalmente (Fig. 12), se trata de ascensos según chimeneas cilíndricas que a veces se acrecionan para dar cuerpos tabulares de mayores dimensiones.

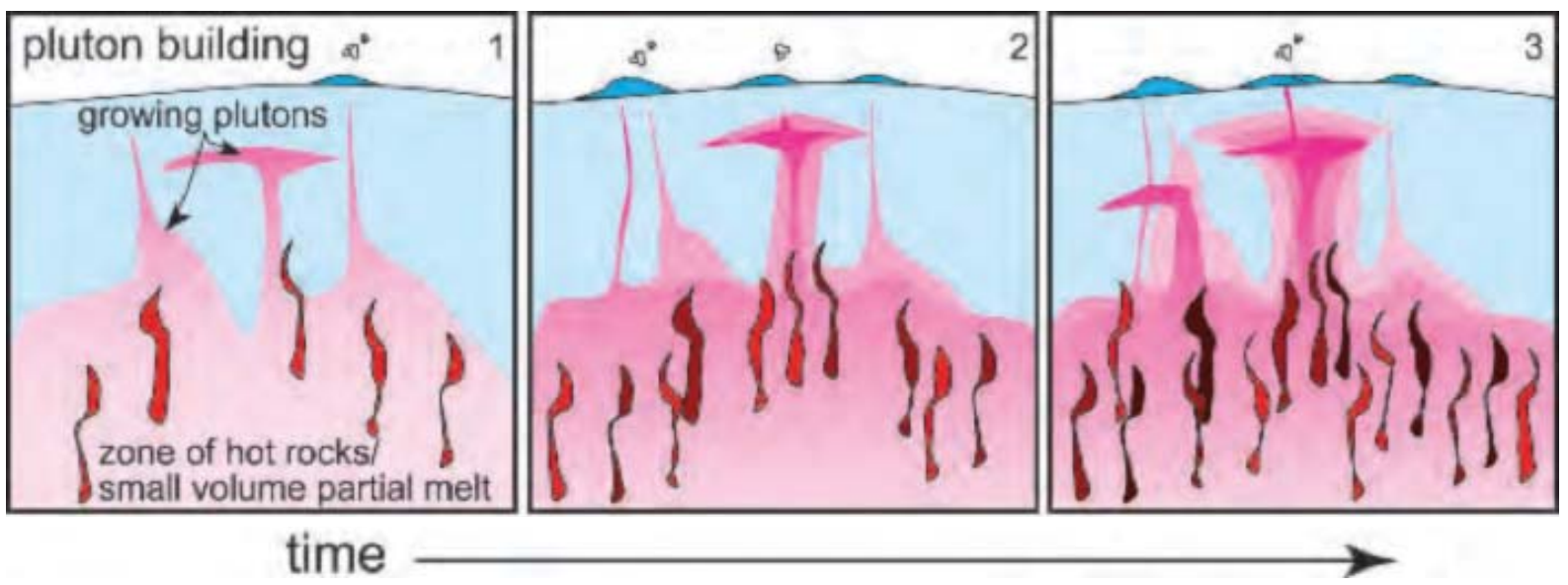

Fig. 12. (Modificado de Glazner et al., 2004). Secuencia de movilización del mush en cuerpos cilíndricos y tabulares en una zona de la litosfera térmicamente activa.

Sin embargo estas movilizaciones no son de magma fundido sino de roca, ya cristalizada, por tanto, (Cashman et al., 2017), una masa mineral sólida que contiene una fracción residual fundida, (entre un 5 y un $20 \%$ y que recibe el nombre de mush. El movimiento del mush, es factible gracias a sus propiedades reológicas que permiten un fácil desplazamiento, aun en el interior de la litosfera (Cashman et al., 2017). El mush, tiene además una gran capacidad de deformación cuando está sometido a esfuerzos, incluso en condiciones compresivas como las existentes en el interior de la litosfera.

En el caso del Domo de Pão de Açucar podemos ver claramente en la cara sur (Fig. 11) una prueba de esta estructura deformativa (F.S.). En la siguiente etapa se generará la fábrica estructural planar o estructura de descamación (sheet structure), la mas característica que es la que define normalmente la morfologia del domo (S.S.)., (Román
Berdiel, 1995; Glatzner et al., 2004; VidalRomaní, 2004, 2008).

Está asociada espacialmente al contacto entre roca encajante con el gnéis glandular como se puede ver claramente en la vertiente sur del Domo de Pão de Açucar (Figura 11) aunque el desmantelamiento del relieve ha producido la pérdida casi completa de la envuelta externa de la que tan solo quedan algunos restos. Este tipo de deformación puede dar lugar a estructuras como la sheet structure, pseudobedding, boudinage, chocolate tablet o polygonal cracking, etc., (Twidale y Vidal Romaní, 1994, 2005) frecuentes en todos los cuerpos de rocas magmáticas intrusivas. El hecho de que sea posible ver formas similares con idéntico aspecto también en rocas sedimentarias (Ramsay y Huber, 1987) cuando han sido plegadas y deformadas, (Ramsay y Huber, 1987; Zulauf et al., 2011 a y b) que obviamente se produce en condiciones superficiales justi- 
fica que, algunos autores, (Twidale, 1982; Gutiérrez y Gutiérrez, 2016) atribuyan la misma génesis para esas estructuras deformativas tanto si se desarrollan en rocas sedimentarias como si lo hacen en rocas plutónicas. Es así como algunos autores tratan de explicar su origen, en ambos casos, por descarga erosiva, desecación-humectación o incluso alteración bajo el suelo (Twidale, 1982), un problema interpretativo, que aqui hemos tratado de aclarar asignando el origen de la forma domo y la sheet structure al proceso endógeno de intrusion de la roca plutónica en la litosfera. Es evidente que, a pesar de todo, aun existe un desconocimiento generalizado del comportamento de las rocas plutónicas desde que se generan en una zona de subducción hasta que intruyen en la litosfera y se enfrían/consolidan definitivamente.

De todas las discontinuidades que se desarrollan en una roca magmática plutónica (granitoide) durante su intrusión la mas relevante morfológicamente es sin duda alguna la exfoliación (sheet structure) pues es la que define en gran parte la morfologia de los morros (bornhardt), la forma mas notoria (aunque no la única ni tampoco exclusiva), de los relieves de rocas magmáticas plutónicas (Twidale y Vidal Romaní, 2005). Durante mucho tiempo se han interpretado los bornhardt (morros) (Twidale y Vidal Romaní, 1994, 2005) como formas erosivas, remanentes que sobreviven al retroceso del escarpe, formas multietapa erosivas, monadnocks de résistance o formas gravadas (Twidale y Vidal-Romaní, 1994). Otros autores, (Tahiri et al., 2007) han interpretado estas descontinuidades, los bornhardt (morros) y las formas relacionadas con ellos, como "the strain aureole", entendiéndolas como estructuras deformativas debidas a la intrusión del mush en la litosfera y las consideran como "estructuras magmáticas desarrolladas en estado solido", (Diot et al., 1987; Petford, 2003), asumiendo que la roca ya estaba consolidada cuando las discontinuidades se formaron (Zulauf et al., $2011 \mathrm{a} \mathrm{y} \mathrm{b).} \mathrm{Todos}$ estos tipos de discontinuidades se localizan próximas al contacto roca plutónica y encajante y siempre se producen en el interior de la litosfera como lo prueba el hecho de que en muchos casos los contactos entre esas discontinuidades han ya sido inyectados por pegmatitas, cuarzo, leucogranito, etc., (Twidale, 1982; Tahiri et al., 2007). Esto es lo que demuestra con claridad la observación del domo de Pão de Açucar.

Sin embargo la sheet structure y otras estructuras relacionadas con ella no son el último episodio deformativo endógeno que afecta a las rocas intrusivas o plutónicas sino el inicio de uno nuevo. En efecto, otra forma asociada a los paisajes rocosos graníticos, el tafone se relaciona igualmente con la deformación de un macizo rocoso en el dominio elástico y se desarrolla aproximadamente a la misma profundidad, aunque posteriormente, a la formación de la sheet structure. También el tafone ha sido considerado por algunos autores de origen exógeno atribuyéndose a algún tipo de meteorización: haloclastia, humectación-desecación de la roca, crioclastia, expansióncontracción térmica causada por radiación solar, diferencias litológicas, erosión eólica, alteración edáfica o exfoliación negativa (Twidale y Vidal-Romaní, 2005, Migon, 2006; Gutiérrez y Gutiérrez, 2016). Sin embargo el tafone tiene un origen endógeno estando su formación relacionada directamente con la de la sheet structure, al final de la etapa intrusiva, cuando el cuerpo granítico ya está totalmente cristalizado. Su formación se debe a pequeños desplazamientos entre las hojas de la sheet structure (Fig.13) donde se producirá un contacto en zonas puntuales (proceso de concentración 
de cargas) y entonces por deformación elástica en puntos específicos del contacto entre bloques (deformación puntual en el campo elástico) (Leonhardt y Mönnig 1975; Vidal-Romaní, 1991, 2008) se generarán cargas puntuales de magnitud muy elevada. Los tafoni del Domo Pão de Açúcar se generarían por un proceso de concentración de cargas (en puntos específicos) asociado a las discontinuidades de la sheet structure (Vidal-Romani, 2008). Tentativamente podríamos asignar tanto la formación de la sheet structure como los tafoni al Neoproterozoico, edad de formación de los gneises graníticos y de lo que ahora vemos de ellos: los morros de la Bahía de Guanabará aunque entonces no estarían en superficie sino incluidos dentro de la litosfera. Posteriormente (Asmus y Ferrari, 1978; Almeida y Carneiro 1998), durante el Cenozoico se desarrolla el principal evento erosivo en la zona. Durante esta etapa eventualmente serían expuestos los domos (morros) de la $\mathrm{Ba}-$ hía de Guanabará y comenzaría también en ellos el desmantelamiento de la sheet structure. Una vez expuestas las zonas mas internas del domo por el desprendimiento de algunas de las lajas de la sheet structure las zonas afectadas previamente por el proceso de concentración de cargas comenzarían a evolucionar por desagregación granular y/o en placas desarrollándose entonces las cavidades tipo tafone.

Dada su actual posición a gran altura sobre la base del domo cualquier otra explicación "clasica" relacionando la formación de los tafoni con la meteorización debida a la humedad sería difícil justificar. Bastaría simplemente con que la exposición del domo por desprendimiento de las lajas de la sheet structure pusiera al descubierto esas zonas para que comenzara a actuar el proceso de desagregación mecánica de las zonas de la roca afectadas por la concentración de cargas dando al final lugar a la exposición del tafone.

\section{CONCLUSIONES}

Los tafoni son formas menores del relieve granítico-gnéisico desarrolladas de manera recurrente en la superficies de domos y cadenas montañosas de Brasil. En la ciudad de Rio de Janeiro las cavidades del tipo tafoni se pueden observar asociadas a las grandes formas de los domos y morros del entorno de la Baía de Guanabara. En el domo Pão de Açúcar se han encontrado cavidades de tipo tafoni que se presentan a partir de los 160 metros de altitud, y constituyen un total de 5 cavidades de grandes dimensiones sobre la superficie rocosa de la vertiente norte. Algunos registros fotográficos de los tafoni muestran el característico conjunto de estructuras asociadas: bóvedas y sobre ellas, alvéolos y panales (honeycombs). Las hipótesis del origen de estos tafoni se basan primero en el desarrollo de una estructura de exfoliación de origen intrusivo y que define el desarrollo de una serie de envolventes concéntricas de lajas o láminas (sheet structure). Posteriormente por el proceso de migración y concentración de cargas sobre las discontinuidades (sistemas de fracturas) a diferentes altitudes del Pão de Açúcar, se producirá el desarrollo de las cavidades de mayores dimensiones. La edad de generación de sheet structure y tafone probablemente se pueda asignar a la de generación de los granitos en el Neoproterozoico. Pero solo es en el Mesozoico con la rotura de Pangea cuando comienza el desmantelamiento del relieve y la exposición en superficie de los domos (morros) de gnéis granítico aunque algún autor retrasa esta etapa hasta el Cenozoico. Este trabajo constituye un material de apoyo a la investigación académica sobre el origen y desarrollo de las formas menores de relieve granítico-gnéisico en el Sureste de Brasil. 

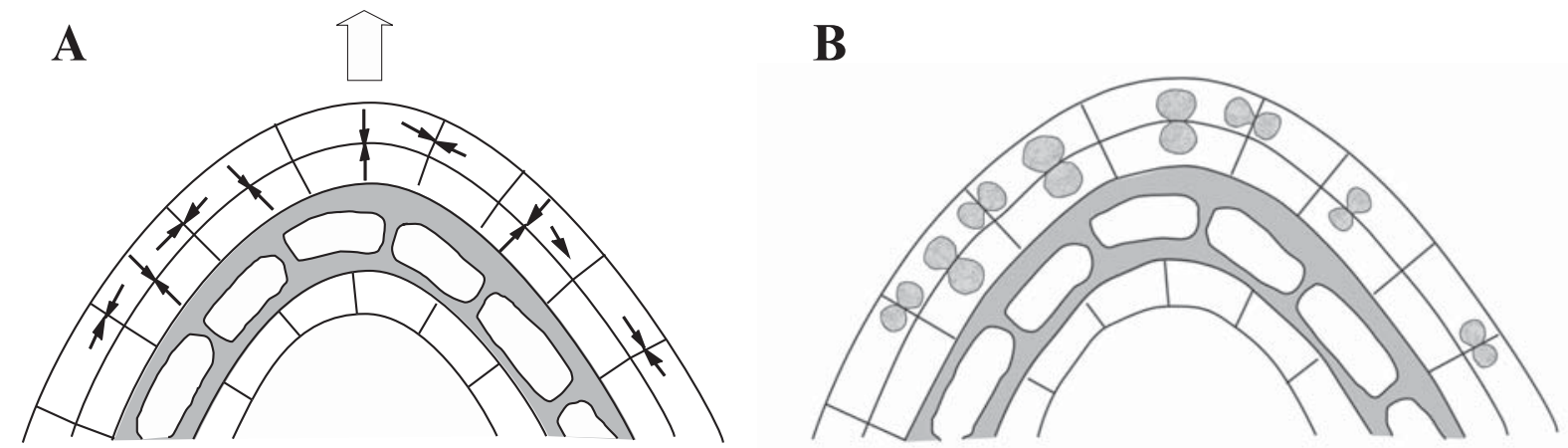

Fig. 13. Esquema de desarrollo del proceso de concentración de cargas en puntos definidos a partir de la sheet structure (a) y creación de espacios lacunares (b) que, una vez se desprende la sheet structure evolucionarán para dar tafoni.

\section{BIBLIOGRAFÍA}

Arzi A. A. 1978. Critical phenomena in the rheology of partially melted rocks. Tectonophysics, 44: 173-184.

Almeida, F.F.M. \& Carneiro, C.D.R. 1998. Origem e evolução da Serra do Mar. Revista Brasileira de Geociências, 28(2): 135-150.

Asmus, H.E. \& Ferrari, A.L. 1978. Hipótese sobre a causa do tectonismo cenozóico na região Sudeste do Brasil. In: PETROBRAS. Aspectos Estruturais da Margem Continental Leste e Sudeste do Brasil (Série Projeto REMAC, 4), Rio de Janeiro, p.5-88.

Auler A.Sarreiro, Cassimiro R., Lima F. T., Maio M.M. 2007. Morphology and génesis of large tafoni in easthern Brazil. International Conference on Granite Caves. A Coruña, Spain. Conference abstracts p. 15.

Bigarella, J.J. 1994. Estrutura e origem das paisagens tropicais e subtropicais volume 1. Florianópolis, Editora UFSC, 425p.

Caldcleugh A. 1829. On the geology of Rio de Janeiro. Transactions of the Geological Society, 2: 69-72.
CECAV-ICMBio. 2010. Identificação de cavidades naturais subterrâneas - Suporte técnico ao processo de licenciamento. EspeleoInfo - Boletim Eletrônico do CECAV. 2(3): 3-3.

Diot H., Bouchez J.L., Boutaleb M., Macaudière J. (1987). Le granite d'Oulmès (Maroc central): structure de l'état magmatic à l'état solide et modèle de mise en place. Bull. Soc. Geol. France t.III, ${ }^{\circ} 1$, 157-168.

Fernandes, N.F., Tupinambá, M., Mello, C.L.; Peixoto, M.N.O. 2010. Rio de Janeiro: A Metropolis Between GraniteGneiss Massifs. In: Migon, P. (Ed.). Geomorphological Landscapes of the World. New York, Springer, p. 89-100.

French S.W.; Romanowick B., (2015). Broad plumes rooted at the base of the Earth's mantle beneath major hotspots. Nature, 525, doi:10.1038/nature14876

Glazner, A. F., Bartley J.M., Coleman D.S., Gray W. A; Taylor R.Z. 2004. Are plutons assembled over millions of years by amalgamation from small magma chambers?. GSA Today,v.14, nº/5. DOI:10.1130/1052-5173. 
Gustafson G., Krásny J. 1993. Crystalline rock aquifers: their occurrence, use and importance. Memories I.A.H. XXIV (Part. 1), 3-20. 24th Congress of International Association of Hydrogeologists. Oslo.

Gutiérrez Elorza M. 2005. Climatic Geomorpholoy. Development in Earth Surface rocesses, 8((Ed. J.F. Shroder Jr). Elsevier Pub. Company. The Netherlands, 753pp.

Gutiérrez F; Gutiérrez M. 2016. Landforms of the Earth. An illustrated guide. Springer Verlag DOI 10.1007/978-3-31926947-4_6.

Landseer, C. 1827. Vista do Pão de Açúcar Tomada da Estrada do Silvestre. In: WIKIPEDIA. Disponível em: < https://pt.wikipedia.org/wiki/ Ficheiro: Charles_Landseer_-_View_ of_Sugarloaf_Mountain_from_the_Silvestre_Road_-_Google_Art_Project. jpg\#globalusage $>$. Acesso em: 28 de agosto de 2018.

Cashman, K.V., Sparks, R. Stephen, J., Blundy, J.D. 2017 Vertically extensive and unstable magmatic systems: A unified view of igneous processes. Science, 355, 6331, 1280.

Maia, R.P. ; Nascimento, M. 2018. Relevos graníticos do Nordeste brasileiro. Revista Brasileira de Geomorfologia, 19(2): 373-389.

Maia, R.P., Nascimento, M.A.L., Bezerra, F.H.R., Castro, H.S., Meireles, A.J.A.; Rothis, L.M. 2015. Geomorfologia do campo de inselbergues de Quixadá - NE do Brasil. Revista Brasileira de Geomorfologia, 16(2): 239-253.

Mayor Rodríguez, J.A. Génesis de Cavidades Graníticas en Ambientes Endógenos y Exógenos. 2011. Coruña, 396p. Tese de
Doutorado, Instituto Universitario de Geología Isidro Parga Pondal, Universidad de Coruña.

Michal Filippi., Bruthans, J., Řihošek, J., Slavík, M., Adamovič, J. ; Mašín, D. 2018. Arcades: Products of stress-controlled and discontinuity related weathering. Earth-Science Reviews.180: 159184.

Migón, P. 2006. Granite Landscapes of the World. New York, Oxford University Press Inc, 416p.

Petford, N. 2003. Rheology of granitic magmas during ascent and emplacement. Annual Review Earth Planetary Science 31, 399-427.

Petit, M. 1971. Contribution a l'etude geomorphologique des reliefs granitiques à Madagascar. Societé Nouvelle de l'Imprimerie Central, Tananarive.

Ramsay J.G.; Huber M.I. 1987. The techniques of modern structural Geology. Vol 2, Fold and Fractures, Academic Press, London, 700 pp.

Román Berdiel M.T. 1995. Mécanismes d'intrusion des granites supracrustaux. Modeles analogiques et exemples naturels. Memoire ${ }^{\circ}$ 62, Geosciences Rennes. Rennes, France. 258 pp.

Roqué C., Zarroca M., Linares R. 2013. Subsurface initiation of Tafoni in granite terrains - Geophysical evidence from NE Spain: Geomorphological implications. Geomorphology 196: 94-105.

Silva, L.C. \& Ramos, A.J.L.A. 2002. Pão de Açúcar, RJ Cartão Postal Geológico do Brasil. In: Schobbenhaus, C., Campos, D.A., Queiroz, E.T., Winge, M. \&Berbert-Born, N. (Ed.). Sítios Geológicos e Paleontológicos do Brasil. Brasília, DNPM, p. 263-268.

Tahiri A., Simancas J.F., Azor A., Galindo 
Zaldivar J, González Lodeiro F., El Hadi H., Martinez Poyatos D.; Ruíz-Constán A. (2007). Emplacement of ellipsoidshaped (diapiric?) granite: Structural and gravimetric analysis of the Oulmès granite (Vaariscan Meseta, Morocco). Journal of African Earth Sciences 48, 301-313.

Twidale C.R. 1982. Granite Landforms. Elsevier Publishing Company, Amsterdam. 372 pp.

Twidale C.R., Vidal-Romaní J.R. 1994. On the multistage development of etch forms. Geomorphology, 11, 157-186.

Twidale, C.R.; Bourne, J.A. 1975. The subsurface initiation of some minor granite landforms. Journal of the Geological Society of Australia 22(4): 477-484.

Twidale, C.R.; Vidal Romaní, J.R. 2005. Landforms and Geology of Granitic Terrains. Leiden, Balkema, 351p.

Twidale, C.R. 1968. Origin of Wave Rock, Hyden, Western Australia. Transactions of the Royal Society of South Australia, 92: 115-123.

Twidale, C.R. 1989. La iniciación subsuperficial de las formas graníticas y sus implicaciones en las teorías generales de evolución del paisaje. Cuaderno do Laboratorio Xeolóxico de Laxe, 13: 49-68.

Twidale, C.R. 2007. Bornhardts and Associated Fracture Patterns. Revista de la Asociación Geológica Argentina, 62(1): 139-153.

Twidale, C.R., Bourne, J.A.; Vidal Romaní, J.R. 2002. Multistage landform development in various settings and at various scales. Cadernos do Laboratorio Xeolóxico de Laxe, 27: 55-76.

Valeriano, C.M., Almeida, J.C.H. ; Heilbron, M. 2003. Precambrian gneisses in Rio de Janeiro: from the Sugar Loaf to the Arpoador outcrops. In: Chaves, H., Camozzato, E., Loguercio S., \& Campos, D.A. (Ed.). Field Trips of the 31st Internacional Geological Congress. SBG/CPRM, Rio de Janeiro.

Vidal-Romaní J.R. 2004. Encyclopedia of Geomorphology Routledge. (sheeting pp.949-950 and pressure release 807808). Taylor and Francis Group. (V. 2), $1156 \mathrm{pp}$.

Vidal-Romaní J.R. 2008. Forms and structural fabric in granite rocks. Cuad. Lab. Xeol.Laxe, 33, 175-198.

Vidal-Romaní J.R.; Yepes Temiño J. 2004. Historia de la morfogénesis granítica. Cadernos do Lab. Xeoloxico de Laxe, 29, 331-360.

Vidal-Romaní, J.R. 1984. Microformas graníticas tipo tafoni (cachola) y gnamma (pía). Un micromodelado sin relación con el clima o la estacionalidad. Caderno Laboratorio Xeolóxico de Laxe, 7: 273-277.

Vidal-Romaní, J.R. 1989. Geomorfología granítica en Galicia (NW España). Cuaderno do Laboratorio Xeolóxico de Laxe, 13: 89-163.

Vidal-Romaní, J.R. 1990. Formas menores en rocas graníticas un registro de su historia deformativa. Cuaderno Laboratorio Xeolóxico de Laxe, 15: 317-328.

Vidal-Romaní, J. R. 1998. Las aportaciones de Casiano de Prado a la geomorfología granítica. Geogaceta 23: 157-159.

Vidal-Romaní, J.R.; Gracia Prieto, F.J. 1987. Formación de cavidades en rocas graníticas bajo condiciones no epigénicas. Cuaderno Laboratorio Xeolóxico de Laxe. 12: 47-57. 
Vidal-Romaní, J.R., Uña Alvarez, E.; Vaqueiro Rodríguez, J. 2014. An endogenous origin for the form tafone developed in magmatic rocks. In: Reunión Nacional de Geomorfología, 8., 2014, Cáceres. Anais... Cáceres, Relieves Graníticos y Cársticos, p. 486-489.

Vidal-Romaní, J.R.; Twidale, C.R. 1998. Formas y Paisajes Graníticos. Coruña, Universidad de Coruña, 411p.

Vidal-Romaní J. R. 1991. Tipos de fabric plana y su relación con la generación de formas graníticas. Cadernos do Laboratorio Xeolóxico de Laxe, 16, 301-312.

Vidal-Romaní J. R. 2008. Forms and structural fabric in granite rocks. Cadernos do Laboratorio Xeolóxico de Laxe, 33,175-198.

Vidal-Romaní J. R., Vaqueiro Rodríguez, M., González López, L., Sanjurjo Sánchez, J. (2014). Bioweathering and development of cavities related to underground water circulation in magmatic rock massifs. Environmental Earth Sciences. DOI:10.1007/s12665-014-3743-2

Vidal-Romaní J.R. 1989. Granite geomorphology in Galicia (NW España). Cuadernos Laboratorio Xeolóxico de Laxe 13: 89-163.

Vidal-Romaní, J. R., Sanjurjo Sánchez, J., Vaqueiro, M., Fernández Mosquera, D. 2010b. Speleothems of Granite Caves. Comunicações Geológicas, 97, 71-80.

Vidal-Romaní, J.R., Twidale C.R. 1998. Formas y paisajes graníticos. $1^{\mathrm{a}}$ edición. Universidade de Coruña, A Coruña, 411 pp.

Vidal-Romaní J.R., Twidale C.R. (1999). Sheet fractures, other stress forms and some engineering implications Geomorphology. 31,1-4: 13-27.

Waldherr, F. Rodrigues, Pinheiro Maia R., Leite do Nascimento A., de Oliveira Rodrigues S., Sarreiro Auler A. 2018. O registro histórico de cavidades do tipo tafoni em terrenos graníticos-gnáissicos do Nordeste do Brasil: o caso da Pedra da Andorinha (CE) e da Gruta do Caboclo (PB). Revista de la Universidad Federal de Rio de Janeiro (en prensa).

Zulauf, G., Gutiérrez-Alonso, G., Kraus, R., Petschick, R., Potel, S. 2011 a. Formation of chocolate-tablet boudins in a foreland fold and thrust belt: A case study from the external Variscides (Almograve, Portugal) Journal of Structural Geology.33, 1639-1649.

Zulauf, J., Zulauf, G., Kraus, R., Gutiérrez-Alonso, G., Zanella, F. 2011 b. The origin of tablet boudinage: Results from experiments using power-law rock analogs. Tectonophysics 510, 327-336. 